\title{
Consumer Preferences for Attributes in Food and Beverages in Developed and Emerging Export Markets and their Impact on the European Union and New Zealand
}

\author{
CAROLINE SAUNDERS \\ Lincoln University \\ Caroline.Saunders@lincoln.ac.nz
}

MEIKE GUENTHER

Lincoln University

JOHN SAUNDERS

Lincoln University

PAUL DALZIEL

Lincoln University

\section{PAUL RUTHERFORD \\ Lincoln University}

\begin{abstract}
This study examined consumer attitudes towards attributes in food and beverages in China, India, Indonesia, Japan and the UK. The attributes included basic attributes such as price and quality, but also extended to food safety and health benefits, as well as environmental and social attributes. The importance of factors affecting key attributes were examined in more detail. The study used a webbased survey with 1,ooo middle and upper income consumers in each country. In addition, the potential economic impact of agricultural returns of different levels of premiums for food attributes in the EU and New Zealand were examined using the partial equilibrium Lincoln Trade and Environment Model (LTEM). This study found that consumers from developing countries valued food attributes more than the developed countries. Trade model projections showed an important impact on the agricultural sectors in the EU and New Zealand from the different levels of premiums for food attributes in selected overseas markets.
\end{abstract}

Keywords: European Union, New Zealand, Food Sustainability, Consumer Preferences, Cross Country Comparison, Trade Modelling

\section{Introduction}

The European Union (EU) and New Zealand are both significant exporters of agricultural commodities. For both regions, it is important to target markets in order to receive greatest value for products. This value can be from taste and quality but also from other attributes. However, consumer preferences for different food attributes are 
likely to vary across different countries and commodities. Credence attributes are qualities believed by a consumer to be present in a product even though they cannot be identified, experienced and inspected by consumers before or after purchase (e.g., food safety, animal welfare, environmental protection and cultural authenticity). The values and consumers' attitudes and preferences towards credence attributes in food have been investigated in several studies worldwide. ${ }^{1}$ However, the literature has tended to be concentrated on consumer preferences in developed country markets such as the United Kingdom (UK), and few studies have been published on how consumers in emerging markets such as India, China and Indonesia evaluate different attributes of food products and how these may compare.

New Zealand and the EU are both dependent on agricultural exports. Historically, New Zealand's main export market has been the UK, but in recent years, the focus of New Zealand exporters has changed: whereas previously almost all exports went to Europe, more are now going to Asian markets, particularly China. Similarly, Asian export markets are important to the EU. ${ }^{2}$ It is therefore important that exporters in New Zealand and the EU understand different cultures and preferences in these markets and how they differ from other markets in order to gain a premium for their exports.

This study is part of a wider research project entitled 'Maximising Export Returns (MER)', a three year project undertaken by the Agribusiness and Economics Research Unit (AERU) at Lincoln University, funded by the New Zealand Ministry for Business, Innovation and Employment (MBIE). This project aims to explore how export firms can capture price premiums by including credence attributes in products for overseas markets. It builds on previous work of the AERU which showed that overseas consumers (including those in the UK, China, and India) value different food attributes in food products. 3 The study particularly showed that food safety was the most important food attribute. Not surprisingly, India and China rated food safety certification as more important than respondents from the UK. However, more surprising was that in most cases Indian and Chinese consumers valued other credence attributes more than in the UK, including organic status, environmental quality, animal welfare and recyclability. In a pilot study, further surveying expanded the research firstly to include more countries such as Indonesia, Japan and Korea, and secondly to assess in more detail the importance of factors affecting key credence attributes in food products and the relationships between them. The pilot survey explored consumer attitudes towards seven attributes in food products and then selected four of them for more detailed analysis. These were animal welfare, environmental quality, health food and food safety. Survey participants were asked to rate the importance of a range of factors underpinning these four attributes, which suggested some associations between them. Environmental quality, for example, was listed in the three developing countries as one of the top five factors associated with

\footnotetext{
${ }^{1}$ Caroline Saunders, Meike Guenther, Peter Tait and John Saunders, Consumer Attitudes and Willingness to Pay for Attributes of Food, In Particular from New Zealand, Proceedings of the 57th AARES Annual Conference, Sydney, 5-8 February, 2013. Canberra, Australia: Australian Agricultural and Resource Economics Society, 2013; Caroline Saunders, Meike Guenther and Timothy Driver, Sustainability Trends in Key Overseas Markets: Market Drivers and Implications to Increase Value for New Zealand Exports, Research Report 319, Lincoln University, NZ: Agribusiness and Economics Research Unit, 2011; Eurobarometer, Europeans' Attitudes towards the Issue of Sustainable Consumption and Production, Analytical report, Bruxelles: European Commission, 2009; Synovate, Global Omnibus Survey on Climate Change', London: Synovate Research, 2007, accessed 30 September 2015, http://www.synovate.com/consumer-insights/infact/issues/200704/

${ }^{2}$ European Commission (EC), Agri-Food Trade in 2014: EU-US Interaction Strengthened, Bruxelles: EC, 2015, accessed 15 October 2015, http://ec.europa.eu/agriculture/trade-analysis/map/2015-1_en.pdf

3 Saunders et al., 2013.
} 
food safety. 4 Results from the pilot survey assisted the development of the scope of this study.

In this study, the selection of credence attributes is expanded to ten attributes in food and beverages that are important to consumers in five New Zealand exports markets. Six of these attributes are selected to assess underpinning factors in more detail. These six key attributes are food safety, environmental condition, animal welfare and health, human health, social responsibility and the role of traditional cultures.

Finally, the potential impact of varying levels of premiums for these attributes in the EU (European Union-28) and New Zealand were examined using the partial equilibrium Lincoln Trade and Environment Model (LTEM).

The paper is structured as follows. The next section gives a brief history of New Zealand and the EU agricultural trade, particularly the rise in importance of emerging markets. Next, the literature on consumer preferences for food attributes, especially in the countries of interest, is reviewed. This is followed by the methodology of the study. Subsequent to this, survey results are presented and discussed, followed by the presentation of the potential impact of different levels of premiums for food attributes upon New Zealand's and EU's producer returns. Finally, brief conclusions are made.

\section{The Importance of Emerging Markets and Consumer Preferences}

Since 2010, China has been New Zealand's key export market for agricultural commodities, facilitated through the signing of a Free Trade Agreement between both countries in 2008. In 2014, the export value of New Zealand's agricultural exports to China was valued at NZ $\$ 8.4$ billion, a $64 \%$ increase from the previous year. 5 In contrast, New Zealand's agricultural exports to India have fluctuated. However, in 2010 India started negotiations towards a Free Trade Agreement with New Zealand, which has the potential for India to become an important export market. ${ }^{6}$ While other Asian markets like Japan and Korea are already well-established trading partners for New Zealand, countries like Indonesia have some trade with New Zealand but have been identified as a potential growth market for the future. In particular, New Zealand's trade relationship with Indonesia has been given impetus by the Association of Southeast Asian Nations (ASEAN) Australia and New Zealand Free Trade Agreement (AANZFTA), of which Indonesia became a member in January 2012.7

Similarly, export markets in Asia are very important for the EU. In 2014, China was the EU's third largest export market in agricultural commodities, with exports worth 7.4 billion Euros. ${ }^{8}$ The EU is committed to enhancing trade relationships with China: in 2013, both countries announced that they would commence negotiations towards a

\footnotetext{
4 Caroline Saunders, Meike Guenther, Timothy Driver, Peter Tait, Paul Dalziel and Paul Rutherford, Consumer Attitudes to New Zealand Food Product Attributes and Technology Use in Key International Markets, Research Report 333, Lincoln University, NZ: Agribusiness and Economics Research Unit, 2015.

5 Statistics New Zealand (SNZ), Global New Zealand - International Trade, Investment and Travel Profile: Year ended June 2014, Wellington, NZ: Statistics New Zealand, 2015.

${ }^{6}$ Ministry of Foreign Affairs and Trade (MFAT), New Zealand-India Free Trade Agreement, Wellington, NZ, MFAT: 2013, accessed 15 October 2015, http://www.mfat.govt.nz/Trade-and-Economic-Relations/2-TradeRelationships-and-Agreements/India/

7 Ministry of Foreign Affairs and Trade (MFAT), ASEAN, Australia and New Zealand Free Trade Agreement, 2014, accessed 30 June 2015, http://www.mfat.govt.nz/Trade-and-Economic-Relations/2-Trade-Relationships-andAgreements/Asean/index.php

8 EC, EU-28 Agri-Food Trade with China, Bruxelles: European Commission, 2015, accessed 15 October 2015, http://ec.europa.eu/agriculture/trade-analysis/statistics/outside-eu/2015/china_en.pdf
} 
comprehensive EU-China Investment Agreement. 9 In addition, India is gaining in importance for the EU, with both countries currently negotiating towards a FTA. ${ }^{10}$ Other important EU export markets in Asia are Taiwan and Singapore for spirits, liquors and vermouth, and Japan for cider and vinegar among others. ${ }^{11}$

With growing trade into emerging markets in Asia, it is important that exporters in New Zealand and the EU understand consumer attitudes towards food and beverages in these markets. There is some literature on consumer preferences in these markets of interest but this varies, and there are only a few studies which compare across countries. For China, studies have shown that food safety is the most important credence attribute for consumers. ${ }^{12}$ Concerns for food safety may have increased since the occurrence of national and international food safety incidents, such as the Fonterra botulism scare in 2013 or the 2008 melamine scare in infant formula. The Chinese government has introduced a number of food safety assurance schemes, including a system of food labels. However, it is argued many consumers have limited trust, as well as limited recognition and understanding of the authenticity of these labels. ${ }^{13}$ In China, "safe food" is also related to the idea of "green food", with a study finding that consumers associate organics with being safer and healthier because of the lack of pesticides and other residues in food. ${ }^{14}$ It is therefore argued that the high interest in organic products is often driven by concerns for health rather than concerns for the environment. 15 Another study found that there is a strong preference by Chinese consumers for food with a health/functional attribute, with women's health and children's health indicated as the strongest concerns. ${ }^{16}$

Food safety is also a key attribute in food for Indian consumers. However, there are only a few studies that have quantified this. Saunders et al. showed that Indian consumers were willing to pay over $70 \%$ for food safety certified dairy and lamb products from New Zealand. ${ }^{17}$ Another study conducted by Birol et al. showed that Indian consumers who were exposed to information on "food safety certified" labelled grapes were more likely to purchase them than those who did not see the additional

\footnotetext{
9 EC, Trade. Policy. China, Bruxelles: European Commission, 2015, accessed 15 October 2015, http://ec.europa.eu/trade/policy/countries-and-regions/countries/china/

${ }^{10}$ EC, Trade. Policy. India, Bruxelles: European Commission, 2015, accessed 15 October 2015, http://ec.europa.eu/trade/policy/countries-and-regions/countries/india/

${ }^{11}$ EC, Agri-Food Trade in 2014: EU-US Interaction Strengthened, Bruxelles: European Commission, 2015, accessed 15 October 2015, http://ec.europa.eu/agriculture/trade-analysis/map/2015-1_en.pdf

${ }^{12}$ Saunders et al., 2013; Yue Zheng, Xianghong Li, and Hikaru Peterson, In Pursuit of Safe Foods: Chinese Preferences for Soybean Attributes in Soymilk, Agribusiness, Vol. 29, No. 3, 2013: pp. 377-391.

13 Ximing Sun and Ray Collins, A Preliminary Study of Chinese Consumers' Willingness-to-Pay for Fruit Produced with Sustainable Attributes, Proceedings on the IV International Symposium on Improving the Performance of Supply Chains in the Transitional Economies, 2012, pp. 349- 354; Xianbing Liu, Can Wang, Tomohiro Shishime, and Tetsuro Fujitsuka, Sustainable Consumption: Green Purchasing Behaviours of Urban Residents in China, Sustainable Development, Vol. 20, 2012: pp. 293-308.

14 John Thøgersen and Yin Zhou, Motives of Organic Food Buyers in China-Do They Differ from Europe?,

Knowledge Collaboration \& Learning for Sustainable Innovation. ERSCP-EMSU Conference, the 14th European Roundtable on Sustainable Production and Consumption (ERSCP), the 6th Environmental Management for Sustainable Universities (EMSU), Delft, Netherlands, 25-29 October, 2010.

${ }^{15}$ Sini Miller, Timothy Driver, Noelani Velasquez, and Caroline Saunders, Maximising Export Returns (MER): Consumer Behaviour and Trends for Credence Attributes in Key Markets and a Review of How These May Be Communicated, Research Report No. 332, Lincoln University, NZ: Agribusiness and Economics Research Unit, 2014.

${ }^{16}$ Hong Kong Trade Development Council (HKTDC), China's Health Food Market, 2013, accessed 20 August 2015, http://china-trade-research.hktdc.com/business-news/article/China-Consumer-Market/China-s-healthfood-market/ccm/en/1/1Xoooooo/1Xoo2L54.htm

17 Saunders et al., 2013.
} 
information. ${ }^{18}$ Some studies have also shown that there is a growing number of Indian consumers who show a preference for environmental attributes associated with food products. ${ }^{19}$ In particular, eco-labelling and eco-friendly packaging has been shown to affect the purchasing decisions of urban middle class Indians. ${ }^{20}$ Similar to China, a study has found that Indian consumers regard organics as a healthier alternative to conventionally produced food due to the lack of pesticide residues rather than environmental concerns. ${ }^{21}$

Similarly, food safety is an important attribute in food for UK consumers, ${ }^{22}$ and this has grown in importance after food safety scares such as the 2013 Horsemeat adulteration scandal 23 and the 2011 German sprouts E. coli outbreak. ${ }^{24}$ Some argue that it is for this reason that country of origin labelling has increased in importance. ${ }^{25}$ UK consumers show a preference for local food, which is often associated with other attributes, including freshness, support for local producers, environmental concerns, better taste, safety, quality and gourmet status. ${ }^{26}$ Other credence attributes that influence purchase decisions of UK consumers including labelling as organic. Similar to China and India, the interest in organics is for reasons other than concern for the

${ }^{18}$ Ekin Birol, Devesh Roy, Katharina Deffner, and Bhushana Karandikar, Developing Country Consumers' Demand for Food Safety and Quality: Is Mumbai Ready for Certified and Organic Fruits?, Contributed Paper prepared for Presentation at the International Association of Agricultural Economists Conference, Beijing, China, 16-22 August 2009.

${ }_{19}$ None Ishaswini and Saroj Datta, Pro-Environmental Concern Influencing Green Buying: A Study on Indian Consumers, International Journal of Business Management, Vol. 6, No. 6, 2011: pp. 124-133; Sabita Mahapatra, A Study on Consumer's Perception for Green Products: An Empirical Study from India, International Journal of Management \& Information Technology, Vol. 7, No. 1, 2013: pp. 924-933; Ravindra Saxena and Pradeep Khandelwal, Can Green Marketing be used as a tool for Sustainable Growth? A Study Performed on Consumers in India - An Emerging Economy, International Journal of Environmental, Cultural, Economic, and Social Sustainability, Vol. 6, No. 2, 2010: pp. 277-291.

${ }^{20}$ Sachin Vernekar and Preeti Wadhwa, Green Consumption: An Empirical Study of Consumers Attitudes and Perception regarding Eco-Friendly FMCG Products, with Special Reference to Delhi and NCR Region, Opinion, Vol. 1, No. 1, 2011: pp. 64-74.

${ }^{21}$ Somnath Chakrabarti, Factors Influencing Organic Food Purchase in India - Expert Survey Insights, British Food Journal, Vol. 112, No. 8, 2010: pp. 902-915; Sushil Kumar and Jabir Ali, Analyzing the Factors Affecting Consumer Awareness on Organic Foods in India, Prepared for Presentation at 21st Annual IFAMA World Forum and Symposium on the Road to 2050: Sustainability as a Business Opportunity, Frankfurt, Germany, 20-23 June 2011; Lauren Finzer, Vamadevan Ajay, Mohammed Ali, Roopa Shivashankar, Shifalika Goenka, Praggay Sharma, Divya Pillai, S. Khandelwal, Nikhil Tandon, Srinath Reddy, Venkat Narayan, and Doraoraj. Prabhakaran, Fruit and Vegetable Purchasing Patterns and Preferences in South Delhi, Ecology of Food and Nutrition, Vol. 52, No. 1, 2013: pp. 1-20.

${ }_{22}$ The Consumer Council, Food Supply Chain Issues and the Horsemeat Scandal - The Consumer View, July 2013, Report, Belfast, UK, 2013; Which?, Horsemeat Scandal Dents Trust in Food Industry, 2013, accessed 30 September 2015, http://www.which.co.uk/news/2013/03/horsemeat-scandal-dents-trust-in-food-industry$313016 /$

23 The Consumer Council, 2013.

24 European Food Safety Authority (EFSA), E.coli: Rapid Response in a Crisis', Bruxelles: EFSA, 2012, accessed 30 September 2015, http://www.efsa.europa.eu/en/press/news/120711.htm

${ }_{25}$ Maria Font i Furnols, Carolina Realini, Fabio Montossi, Carlos Sañudo, Maria Campo, Martin Oliver, Graham Nute, and Luis Guerrero, Consumer's Purchasing Intention for Lamb Meat Affected by Country of Origin, Feeding System and Meat Price: A Conjoint Study in Spain, France and the United Kingdom, Food Quality Preference, Vol. 22, 2011: pp. 443-451; Mintel, A Big Thumbs Up for British Post Horse Meat Scandal - One in Two Brits Now Feel British Food is Better Quality than Imported, 2013, accessed 30 September 2015,

http://www.mintel.com/press-centre/food-and-drink/a-big-thumbs-up-for-british-post-horse-meat-scandalone-in-two-brits-now-feel-british-food-is-better-quality-than-imported; Mintel, Just Half of Brits Trust the Food Industry to Provide Safe Food to Eat, 2013, accessed 28 August 2015, http://www.mintel.com/press-centre/foodand-drink/food-safety-after-horse-meat-scandal

${ }^{26}$ Gareth Edwards-Jones, Llorenc Milà i Canals, Natalia Hounsome, Monica Truninger, Georgia Koerber, Barry Hounsome, and David Jones, Testing the Assertion that Local Food is Best: The Challenges of an Evidence-Based Approach, Trends in Food Science and Technology, Vol. 19, No. 5, 2008: pp. 265-274; Maria Loureiro and Wendy Umberger, A Choice Experiment Model for Beef: What US Consumer Responses Tell Us About Relative Preferences for Food Safety, Country of Origin Labelling and Traceability, Food Policy, Vol. 32, 2007: pp. 496514 . 
environment, such as health (no pesticide use) and as an extension of a healthy lifestyle. ${ }^{27} \mathrm{UK}$ consumers are concerned about animal welfare in food production, with studies showing consumers would be willing to pay extra for products where production followed animal welfare standards. ${ }^{28}$ Some studies found other attributes are important to UK consumers when food shopping and influence purchase decisions. These include ethical production such as Fair Trade and carbon labelling. ${ }^{29}$

Sustainable consumption and production is important to European consumers. Results from a survey undertaken by the European Commission in 2009 across the 28 EU member states showed that the environmental impact of a product is likely to influence consumption habits of European citizens. The majority of participants stated that a product's impact on the environment is an important variable when deciding which product to buy. Results further showed that recycling and reusability was the most desired environmental attribute a product label could contain. The proportion saying that this was important ranged from $57 \%$ in Finland to $18 \%$ in Latvia. ${ }^{0}$

Several studies have assessed Japanese consumers' attitudes towards credence attributes in food. For food safety, Haydon et al. showed that Japanese consumers perceived locally-produced pork safer than imported pork. ${ }^{31} \mathrm{Kim}$ found a food product's country of origin was a key determinant on consumer perception of food risk in Japan. ${ }^{2}$ There is some evidence that Japanese consumers value environmental attributes in food. For example, Uchida et al. showed that Japanese consumers had a higher willingness-to-pay for seafood products labelled for improved environmental quality, 33 and Motoshita et al. found that consumers in Japan indicated that they would adjust their purchase behaviour when given information about how their food choice affects carbon dioxide emissions. 34 A few studies have examined Japanese consumer attitudes to animal welfare in production, with consumers perceiving that locally-produced pork has higher animal welfare credentials than imported products. 35 Previous studies have shown that Japan is one of the world's largest markets for

\footnotetext{
${ }^{27}$ Claire Garcia, Andrew Fearne, and Lisa Wood, The Role of Involvement in the Attention Paid by Supermarket Shoppers to Organic Products, Journal of Innovation Economics and Management, Vol. 1, No. 5, 2010: pp. 127144.

${ }^{28}$ K.A. Ellis, K. Bilington, B. McNeil, and D. McKeegan, Public Opinion on UK Milk Marketing and Dairy Cow Welfare, Animal Welfare, Vol. 18, No. 3, 2009: pp. 267-282; Fabio Napolitano, Corrado Pacelli, Antonio Girolami, and Ada Braghieri, Effect of Information about Animal Welfare on Consumer Willingness to Pay for Yogurt, Journal of Dairy Science, Vol. 91, 2007: pp. 910-917; Giuseppe Nocella, Lionel Hubbard, and Ricardo Scarpa, Farm Animal Welfare, Consumer Willingness to Pay, and Trust: Results of a Cross-National Survey, Applied Economic Perspectives and Policy, Vol. 32, No. 2, 2010: pp. 275-297.

29 Felix Nandonde, Consumers' Attitude towards Fairtrade Coffee in the UK, DBA Africa Management Review, Vol. 2, No. 2, 2012: pp. 1-13; Meike Guenther, Caroline. Saunders, and Peter Tait, 'Carbon Labeling and Consumer Attitudes, Carbon Management Journal, Vol. 3, No. 5, 2012: pp. 445-455; Zaina Gadema and David Oglethorpe, The Use and Usefulness of Carbon Labelling Food: A Policy Perspective from a Survey of UK Supermarket Shoppers, Food Policy, Vol. 36, No. 6, 2011: pp. 815-822.

$3^{\circ}$ Eurobarometer, 2009.

${ }^{31}$ Peter Haydon, Darryl D'Souza, and Heather Channon, Defining the Relative Importance of Consumer Drivers and Perceptions of Australian Pork in Targeted Export Markets, Report prepared for the Co-operative Research Centre for High Integrity Australian Pork, March 2013.

${ }^{32}$ Renee Kim, Japanese Consumers' Use of Extrinsic and Intrinsic Cues to Mitigate Risky Food Choices, International Journal of Consumer Studies, Vol. 32, 2008: pp. 49-58.

33 Hirotsugu Uchida, Yuko Onozaka, Tamaki Morita, and Shunsuke. Managi, Demand for Ecolabeled Seafood in the Japanese Market: A Conjoint Analysis of the Impact of Information and Interaction with Other Labels, Food Policy, Vol. 44, 2014: pp. 68-76.

34 Masaharu Motoshita, Masaji Sakagami, Yuki Kudoh, Kiyotaka Tahara, and Atsushi Inaba, Potential Impacts of Information Disclosure Designed to Motivate Japanese Consumers to Reduce Carbon Dioxide Emissions on Choice of Shopping Method for Daily Foods and Drinks, Journal of Cleaner Production, Vol. 101, 2015: pp. 1-10. 35 Haydon et al., 2013.
} 
functional foods, $3^{6}$ with nearly 970 FOSHU-certified 37 products available on the domestic market in 2011,38 and that Japanese consumers incorporate these products into their diets. 39

Only a few studies have assessed consumer preferences for credence attributes in Indonesia, and even fewer with the in-depth analysis relative to those of the UK, the EU, China, India and Japan. Some inferences can be made with the information that does exist. Some studies suggest that consumer demand for environmental and ethical attributes in food products does exist and may be increasing in the Indonesian food market. 40 There is particular demand for organic products as part of an increasing interest in healthy lifestyles. 41

To summarise, the reviewed studies indicate that credence attributes in food products are relevant to consumers in overseas markets; however, there is still little known about consumers' attitudes and preferences for credence attributes of food products in some emerging markets in Asia and also between those countries.

\section{Method}

The method included a structured and self-administered survey. Five surveys were conducted in April 2015. The surveys involved two developed countries (Japan and the UK) and three developing countries (China, India and Indonesia). The survey was administered through Qualtrics ${ }^{\mathrm{TM}}$, a web-based survey system, and had a sample size of 1,000 consumers in each country.

The sampling strategy for the surveys involved the recruiting of participants from an online panel database of consumers. Each survey was stratified by household income distribution. The original survey was in English. For the Chinese, Japanese and Indonesian survey, the questionnaire was translated into the respective language by a professional translation service and cross-checked by another translation service. Survey respondents were screened out by income, if they were not going grocery shopping at least once a month and if they did not know New Zealand as a country. In particular, the screen by income was used to target the upper and middle class in each country.

The survey was comprised of a range of questions constructed to assess consumers' attitudes and preferences towards a number of attributes of food and beverages. These attributes included basic food attributes, such as quality, price, food safety, and

\footnotetext{
${ }^{36}$ Sumeet Kaur and Madhusweta Das, Functional Foods: An Overview, Food Science and Biotechnology, Vol. 20, No. 4, 2011: pp. 861-875; Teck-Cai Lau, Mei-Wan Chan, Hoi-Piew Tan, and Choon-Long Kwek, Functional Food: A Growing Trend among the Health Conscious, Asian Social Science, Vol. 9, No. 1, 2012: pp. 198-208.

37 Food for Specific Health Uses (FOSHU) is the Japanese national standard for functional food certification.

${ }^{38}$ Makato Shimizu, Functional Food in Japan: Current Status and Future of Gut-Modulating Food, Journal of Food and Drug Analysis, Vol. 20, No. 1, 2012: pp. 213-216.

39 Rasa Krutulyte, Klaus Grunert, Joachim Scholderer, Liisa Lähteenmäki, Kit Hagemann, Peter Elgaard, Brian Nielsen, and Jens Graverholt, Perceived Fit of Different Combinations of Carriers and Functional Ingredients and its Effect on Purchase Intention, Food Quality Preference, Vol. 22, 2011: pp. 11-16.

$4^{\circ 0}$ Ririn Wulandari, Budi Suharjo, Agus Soehadi, and Herry Purnomo, Characteristic and Preferences of Green Consumer Stratification as Bases to Formulating Marketing Strategies of Ecolabel-Certified Furniture, Issues in Social and Environmental Accounting, Vol. 6, 1/2, 2012: pp. 123-141.

${ }^{41}$ Kurnia, Ximing Sun, and Ray Collins, Consumers Perceptions toward Organic Food in Yogyakarta, Indonesia, Proceedings of the IV th $I S$ on Improving the Performance of Supply Chains in Transitional Economics, Cebu, Phillippines, 4-7 July 2012; Asep Hermawan and Husna Yusran, Healthy Lifestyle and Consumer Willingness to Pay Organic Foods, The 2nd IBSM, International Conference on Business and Management, Chiang Mai, Bangkok, Thailand, 2-4 October 2013.
} 
nutritional value, but also social and environmental attributes, such as animal welfare and health, traditional cultures, human health enhancing foods, social responsibility and environmental condition. This was followed by a more detailed assessment of the importance of underpinning factors for six key attributes in food and beverages in order to assess the relationships between them. The attributes were food safety, environmental condition, animal health and welfare, health enhancing foods, social responsibility, and traditional cultures. Finally, the survey included questions on ranking food and beverages from different countries. The survey also included a choice experiment to assess consumers' willingness-to-pay (WTP) for certain food attributes in dairy products, meat products, fruit and vegetables, and wine. The detailed WTP results of the choice experiment are, however, not in the scope of this paper.

The study then analysed the potential impact of varying levels of premiums for food attributes in different countries on producer returns in the EU (European Union-28) and New Zealand using the Lincoln Trade and Environment Model (LTEM), which is a multi-country, multi-commodity partial equilibrium (PE) model of international trade..$^{2}$ The model focuses on the agricultural sector and was specifically modified to focus on New Zealand and the EU, their main trading partners and their policies. The LTEM includes 23 countries or regions (including the rest of the world (ROW)) and 23 commodities. The base year is 2012, simulating out to 2024 .

\section{Results and Discussion}

This section reports on results from the surveys conducted in China, India, Indonesia, Japan and the UK. In addition, modelling results of the potential impact of varying levels of premiums for credence attributes on the EU (European Union-28) and New Zealand are described.

\section{Consumer Preferences for Credence Attributes in Food and Beverages across Countries}

Based on a five-point Likert scale varying from very important to not important at all, participants were asked to rate the importance of ten key attributes when shopping for food and beverages. These were quality, price, animal health, animal welfare, environmental condition, health enhancing foods, food safety, social responsibility, nutritional value, and traditional cultures. Figure 1 shows the percentage of replies in each country that responded important or very important to those ten attributes.

\footnotetext{
${ }^{42}$ Selim Cagatay and Caroline. Saunders, Lincoln Trade and Environment Model: An Agricultural Multi-Country Multi-Commodity Partial Equilibrium Framework, Research Report No. 254, Lincoln University, NZ: Agribusiness and Economics Research Unit, 2003; Selim Cagatay and Caroline Saunders, Trade and Environment: Economic and Environmental Impacts of an Agricultural Emissions Policy in New Zealand, Journal of Environmental Assessment Policy, Vol. 6, No. 3, 2004: p. 28; Caroline Saunders, Anita Wreford, and Selim Cagatay, Trade Liberalization and Greenhouse Gas Emissions: The Case of Dairying in the EU and New Zealand, Australian Journal of Agricultural and Resource Economics, Vol. 50, No. 4, 2006: pp. 538-555, doi:10.1111/j.1467-8489.2006.00343.x.
} 


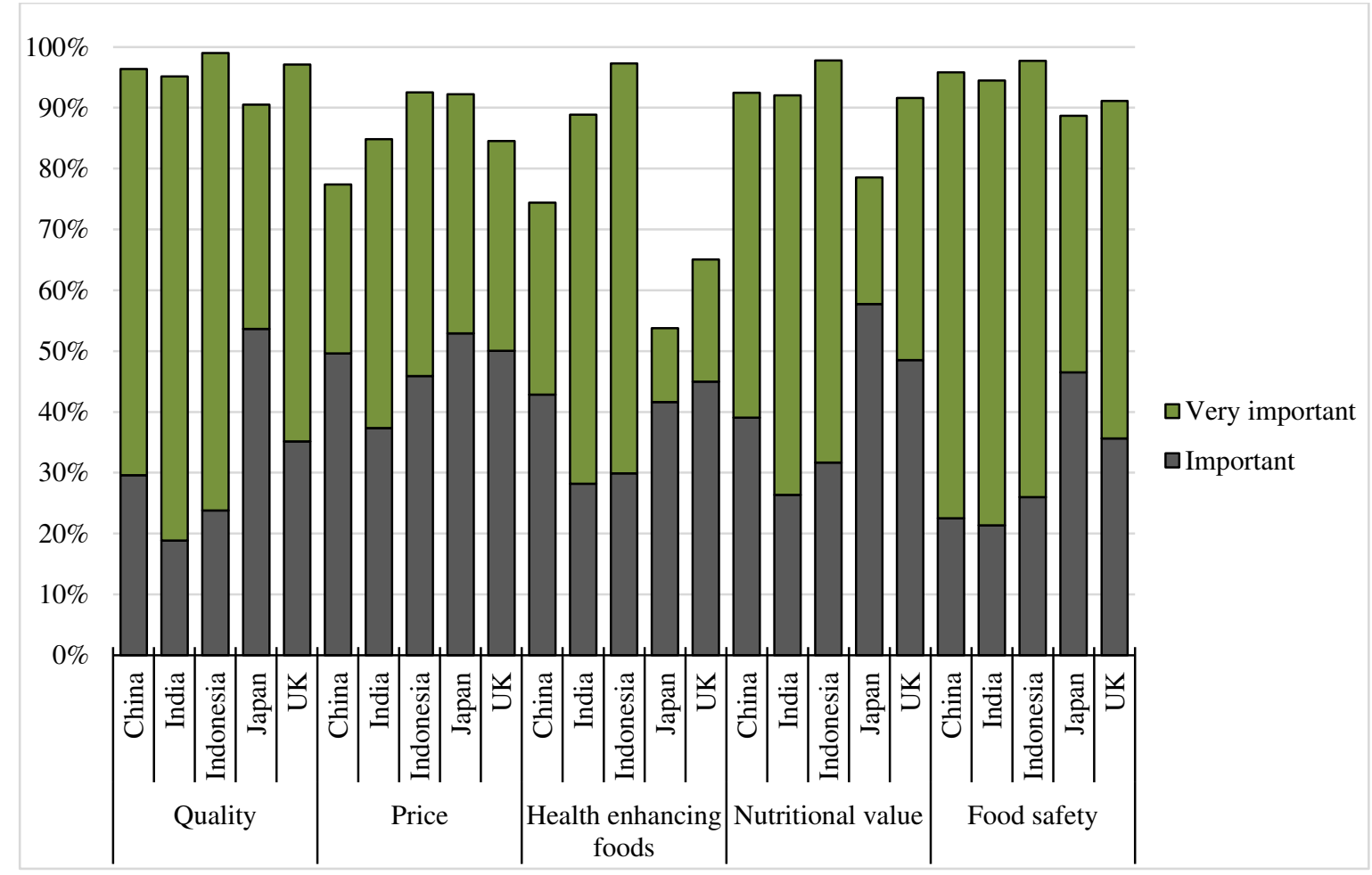

Fig 1. Importance of attributes in food products (in \%)

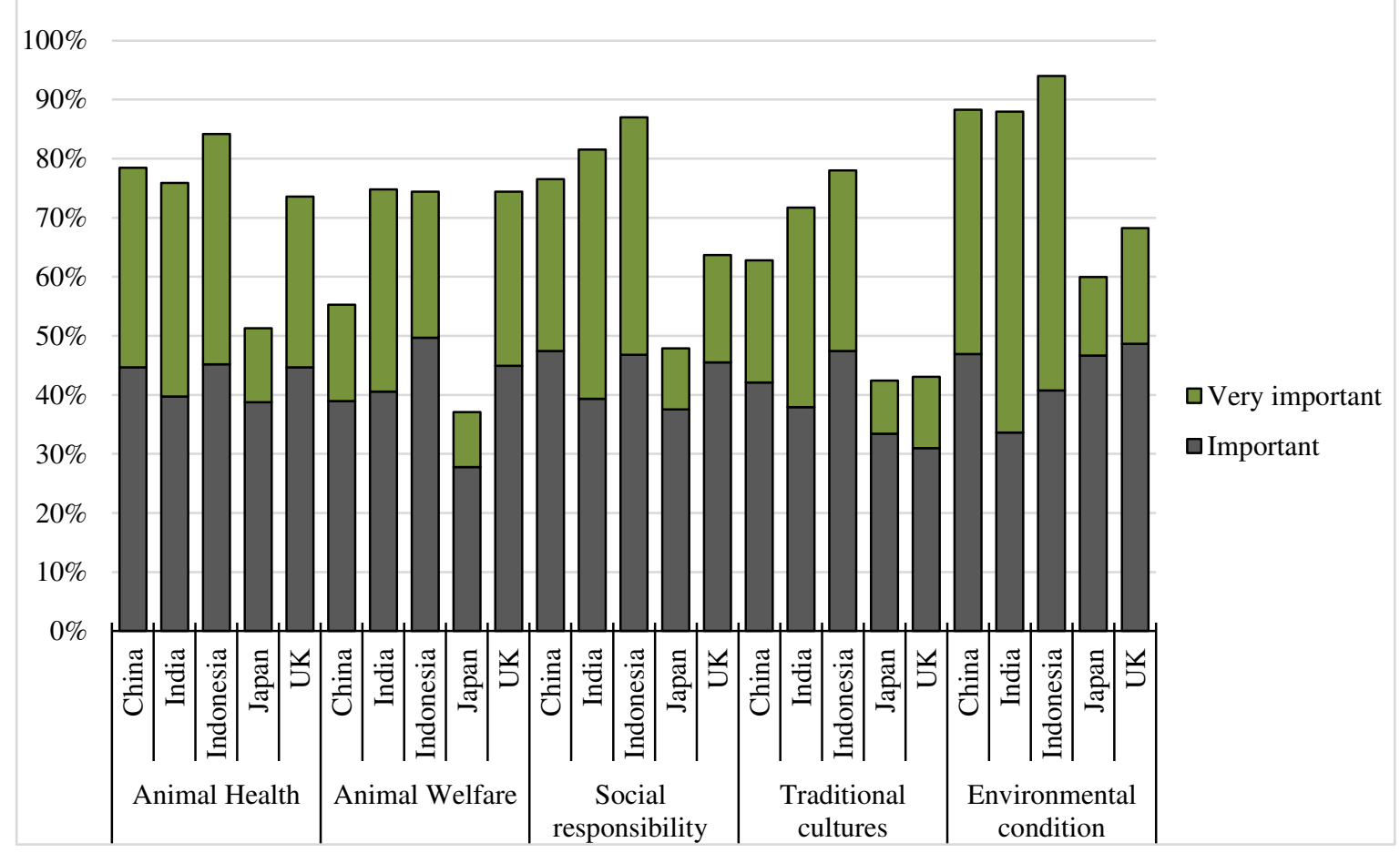

Fig 1 (continued). Importance of credence attributes in food products (in \%)

As shown in Figure 1, quality was the most important of the ten attributes, with a higher percentage of respondents from developing countries compared to developed countries stating this was very important. This may reflect the different supply chains in these countries and the controls over these. 
Food safety was the second most important of the ten attributes in all countries, with an average of $94 \%$ of respondents across all countries indicating food safety was either very important or important when food shopping for food and beverages. This was highest in Indonesia at $98 \%$ and lowest in Japan at $89 \%$. Nutritional value was the third most important of the ten attributes in all countries. It was particularly important to Indonesian participants, with $98 \%$ indicating this was important and very important.

Environmental condition was considered important and very important across all markets, with the highest percentage from respondents in Indonesia (94\%), followed by China and India at $88 \%$, each, then the UK (68\%) and Japan (60\%). Animal health was considered more important by respondents across all countries than animal welfare. For both attributes, Indonesian respondents indicated the highest importance and Japanese the lowest.

The attribute of social responsibility when shopping for food and beverages was of less importance to respondents across all countries; and of all the attributes, traditional cultures when shopping for food and beverages was the least important, particularly among Japanese respondents, of whom only $9 \%$ rated the attribute as very important.

Overall, all attributes were rated higher in importance by respondents in developing countries than in developed countries. This is in line with a previous study by Saunders et al. where Indian and Chinese consumers valued credence attributes in food products more than consumers in the UK, especially for organic status, environmental quality, animal welfare and recyclability.

\section{Importance of Factors in Relation to Key Attributes in Food and Beverages Supply}

In the next set of questions, participants were asked to rate on a five-point Likert scale varying from very important to not important at all the importance of a set of factors underpinning each key attribute in food and beverages supply. The six key attributes were food safety, environmental condition, animal welfare and health, human health, social responsibility and the role of traditional cultures.

Results showed that almost consistently, the developing countries considered all factors to be more important than the developed countries. For food safety, participants from all surveyed countries rated freshness, hygiene standards and labelling of "use by date" as the most important factors associated with this attribute. Cross-country comparisons showed that for Chinese participants, hygiene standards associated with food safety were rated the most important while Indonesian and Indian participants indicated the labelling of a product's "use by date" to be the most important factor associated with food safety. For Japanese and UK participants, freshness was the most important factor underpinning food safety. Animal welfare as a factor related to food safety was the least important across all countries, except in the UK, where GM-free food was the least important factor related to food safety.

The survey also asked participants to consider the importance of factors as they relate to environmental condition in food and beverages supply. Almost consistently, the developing countries considered all factors to be more important to environmental condition than the developed countries, with the most important factors being water and air quality and recycling. These results were consistent with findings from 
previous research. 43 While Indian, Indonesia and Chinese respondents indicated that organic production is an important factor related to environmental condition, Japanese respondents showed that recycling was an important factor for this attribute. The factor of protecting endangered species in relation to environmental condition in the supply chain was particularly important to respondents from the UK and Indonesia. Protecting wetlands in association with environmental condition in the supply chain was among the least important factors across all countries.

When asked about the importance of factors related to animal welfare and health, participants in all markets considered free of disease, good quality of life and animals are well-fed as the most important factors. In contrast, the least important factors related to animal welfare and health were free range and the existence of a welfare veterinary plan. While respondents from the developing countries rated most of the factors higher in importance than respondents from the developed countries, results showed that respondents from the UK placed higher importance on the factors free of disease, no cruelty and humane slaughter than respondents from the other countries. For Chinese participants, free of disease and mainly pasture fed were important factors in relation to animal welfare and health, while Indians placed a high importance on natural conditions. Japanese participants reported high importance for the factors free of disease, animals are well-fed animals and good quality of life.

With regards to the importance of factors related to health-enhancing foods, results were more varied and different factors related to health foods were important to participants in different countries. Across all countries, heart and cholesterol health, digestive health, and child health were the most important factors. Country-specific comparisons showed a large variation in consumer preferences for these factors, especially compared to results of previous attributes and their underpinning factors. While Chinese participants placed highest importance on the factors of digestive health, immune system and baby health, Indian participants rated child health, baby health and the immune system highly important. Indonesian participants rated heart and cholesterol health, child health and digestive health as very important. Japanese participants reported bone health, digestive health, and heart and cholesterol health were important factors in relation to health-enhancing foods, while their fellow UK participants rated heart and cholesterol health, digestive health and child health as most important. Mobility as a factor related to health-enhancing foods was among the least important factors across all countries. Weight management was low in importance for consumers from the developing countries while energy and endurance was low in importance for consumers from the developed countries.

When asked about the importance of factors related to social responsibility, participants from all countries rated the factors of workplace safety, good working conditions, and fair wages as the most important in relation to social responsibility in food and beverages supply. Country-specific consumer preferences showed that for Chinese, Indonesian and Japanese participants, the factor workplace safety was seen as the most important, while Indian participants indicated good working conditions was the most important factor. UK participants indicated that no child labour was the most important factor in relation to social responsibility. Freedom to join a trade union as a factor related to social responsibility in the supply chain was rated lowest in

43 Saunders et al., 2013; Saunders et al., 2015. 
importance in the developing countries, while investment of profits in community facilities was rated lowest in importance in the developed countries.

Finally, the survey asked participants to indicate the importance of several factors when considering the role of traditional cultures in food and beverages supply. Preferences for factors associated with this attribute were very similar across all countries, with participants rating the factors of care for future generations, equity and fairness and connection with natural environment as the most important factors. Interestingly, the factor of indigenous rights was rated relatively high by participants from the UK when compared to the other countries. Family business as a factor related to traditional cultures was rated lowest in importance across all countries (except Indonesia and the UK).

\section{Attitudes towards Food and Beverages from Different Countries}

Participants were asked to rank food and beverages from different countries and/or regions, including Australia, Europe, Japan, Korea, New Zealand, North America and South America, as well as from their own country. As Table 1 shows, participants from China and Indonesia ranked New Zealand products the highest from the list of countries. This was followed by Indians, who ranked New Zealand food and beverages second highest after their own country's products. Participants from Japan and the UK ranked products from their own country the highest and products from New Zealand third from the list. Products from Europe were relatively highly ranked across all countries, while products from North and South America were ranked relatively low by all participants.

\begin{tabular}{|l|c|c|c|c|c|}
\hline & China & India & Indonesia & Japan & UK \\
\hline My own country & 4 & 1 & 4 & 1 & 1 \\
\hline Australia & 3 & 3 & 5 & 2 & 4 \\
\hline Europe & 2 & 4 & 3 & 4 & 2 \\
\hline Japan & 6 & 6 & 2 & N/A & 6 \\
\hline Korea & N/A & N/A & N/A & 6 & N/A \\
\hline New Zealand & $\mathbf{1}$ & $\mathbf{2}$ & $\mathbf{1}$ & $\mathbf{3}$ & $\mathbf{3}$ \\
\hline North America & 5 & 5 & 6 & 7 & 5 \\
\hline South America & 7 & 7 & 7 & 5 & 7 \\
\hline
\end{tabular}

Table 1. Ranking of food and beverages from different countries and or/ regions Note: $\mathrm{n} / \mathrm{a}=$ not applicable

\section{Impacts from Different Premiums for Credence Attributes in Food across Different Countries}

Results from previous studies undertaken by the AERU have shown that consumers in developed and developing countries would be willing to pay premiums for credence attributes in food products (e.g., food safety, animal welfare, environmental 
sustainability). 44 However, Saunders et al. (2013) showed that the level of these premiums differed between countries. They ranged from $20 \%$ for biodiversity enhancement certification of food products to $75 \%$ for food safety certified products. Thus, the study particularly showed that food safety was the most important food attribute across countries. 45

In order to assess the potential economic impact of these premiums on the EU and New Zealand, a total of four scenarios were developed, simulating varying levels of premiums for food attributes in different countries. In the first two scenarios, it was assumed that firstly a premium of $20 \%$ and secondly a premium of $50 \%$ was achieved for food in three developing countries (India, China, Indonesia). Further, two scenarios were developed in which it was assumed that both of these premiums were achieved in the three developing countries of China, India and Indonesia, as well as in six developed countries, including Australia, Canada, Europe Union (28), Korea, Japan and the United States of America. The scenarios are listed in Table 2. The base scenario represents the business-as-usual situation with no premiums for attributes applied. In all scenarios, premiums were applied to all commodities in the model.

\begin{tabular}{l|l}
\hline Scenario & Type \\
\hline BL & Baseline \\
\hline $1-1$ & $20 \%$ increased value in developing countries \\
\hline $1-2$ & $50 \%$ increased value in developing countries $^{(1)}$ \\
\hline $2-1$ & $20 \%$ increased value in developed $^{(1)}$ and developing countries \\
& $(2)$ \\
\hline $2-2$ & $50 \%$ increased value in developed $^{(1)}$ and developing countries $^{(2)}$ \\
\hline
\end{tabular}

Table 2. Modelling Scenarios

Note: (1) These countries included China, India and Indonesia.

(2) These countries included Australia, Canada, Europe Union (28), Korea, Japan and the United States of America.

The potential impact of different ranges of premiums for credence attributes on producer returns was modelled using the LTEM. As mentioned above, four scenarios were developed assuming different premiums for credence attributes in food in different countries. For each scenario, the percentage changes in 2024 compared to the baseline in 2024 are shown as impacts on producer returns in the EU and New Zealand for two meat commodities (i.e., beef, sheep meat) and four dairy commodities (i.e., butter, cheese, whole milk powder, skim milk powder).

\footnotetext{
44 Saunders et al., 2013; Guenther et al., 2012; Peter Tait, Caroline Saunders, Paul Rutherford, and Meike Guenther, Valuation of Sustainability Attributes of Food Products in India and China: Decomposing the Value of New Zealand's 'Clean-Green’ Brand,' Proceedings of the NZARES Conference, Lincoln, NZ, 29-30 August 2013. 45 Saunders et al., 2013.
} 


\begin{tabular}{c|cccc}
\hline & \multicolumn{2}{|c}{$\begin{array}{c}\text { 20\% premium on } \\
\text { credence attributes in } \\
\text { food }\end{array}$} & $\begin{array}{c}\text { 50\% premium on } \\
\text { credence attributes in } \\
\text { food }\end{array}$ \\
\cline { 2 - 5 } & EU-28 & NZ & EU-28 & NZ \\
\hline Beef & 6 & 8 & 16 & 21 \\
\hline Sheep meat & 10 & 16 & 25 & 42 \\
\hline Butter & 31 & 5 & 80 & 11 \\
\hline Cheese & 3 & 4 & 7 & 10 \\
\hline $\begin{array}{c}\text { Whole milk } \\
\text { powder }\end{array}$ & 6 & 8 & 14 & 18 \\
\hline $\begin{array}{c}\text { Skim milk } \\
\text { powder }\end{array}$ & 7 & 7 & 17 & 18 \\
\hline
\end{tabular}

Table 3. Change to New Zealand (NZ) and European Union (EU-28) producer returns from premiums for credence attributes in food in developing countries ${ }^{(1)}$ by selected commodities to 2024, in \% (changes base to scenario)Note: (1) These countries included China, India and Indonesia.

Scenario 1-1 assumed a 20\% premium for credence attributes in food in three developing countries (China, India and Indonesia). As shown in Table 3, for New Zealand, the largest increase in producer returns was predicted from sheep meat, expected to increase by $16 \%$ by 2024 , while the largest increase in EU producer returns was predicted for butter, increasing by $31 \%$.

In Scenario 1-2, which simulated premiums of 50\% for credence attributes in food in three developing countries, model projections showed the potential increase in EU producer returns was the highest for cheese, accounting for an increase of $80 \%$ by 2024. New Zealand producer returns from sheep meat were predicted to grow by $42 \%$, followed by beef returns, which accounted for an increase of $21 \%$ by 2024 . Hence, in this scenario, increases in New Zealand producer returns from meat were higher than increases from dairy.

\begin{tabular}{c|cccc}
\hline \multirow{2}{*}{} & \multicolumn{2}{|c}{$\begin{array}{c}\text { 20\% premium on } \\
\text { credence attributes in } \\
\text { food }\end{array}$} & $\begin{array}{c}\text { 50\% premium on } \\
\text { credence attributes in } \\
\text { food }\end{array}$ \\
\cline { 2 - 5 } & EU-28 & NZ & EU-28 & NZ \\
\hline Beef & 17 & 22 & 44 & 60 \\
\hline Sheep meat & 13 & 23 & 31 & 62 \\
\hline Butter & 52 & 9 & 137 & 19 \\
\hline Cheese & 29 & 29 & 79 & 79 \\
\hline $\begin{array}{c}\text { Whole milk } \\
\text { powder }\end{array}$ & 5 & 8 & 11 & 19 \\
\hline $\begin{array}{c}\text { Skim milk } \\
\text { powder }\end{array}$ & 26 & 22 & 71 & 60 \\
\hline
\end{tabular}

Table 4. Change to New Zealand (NZ) and European Union (EU-28) producer returns from premiums for credence attributes in food in developing ${ }^{(1)}$ and developed ${ }^{(2)}$ countries by selected commodities to 2024 , in $\%$ (changes base to scenario) Note: (1) These countries included China, India and Indonesia.

(2) These countries included Australia, Canada, Europe Union (28), Korea, Japan and the United States of America. 
Scenario 2-1 assumed a 20\% premium for credence attributes in food in three developing and six developed countries. As shown in Table 4, for New Zealand the largest increase in producer returns was expected from cheese, which was projected to increase by $29 \%$ by 2024 , followed by sheep meat (+23\%). For the EU, the largest increase was projected for producer returns from butter $(+52 \%)$, then cheese $(+29 \%)$. EU producer returns from WMP were predicted to increase by only 5\% by 2024 .

For both the EU and New Zealand, the most significant effects on producer returns were predicted in Scenario 2-2, in which premiums of 50\% for food attributes in developing and developed countries were assumed. Modelling results showed that EU producer returns from butter were predicted to more than double by 2024, followed by returns from cheese $(+79 \%)$. The highest increase in New Zealand producer returns was predicted for cheese, which was predicted to almost double by 2024, followed by sheep meat which was predicted to increase by $62 \%$ in the same period.

\section{Conclusion}

Several studies have examined consumers' attitudes and preferences towards different food attributes across countries. However, there are only a few studies that have assessed consumer attitudes towards basic food attributes and the product's environmental and social performance in emerging markets in Asia and also between those countries. These emerging markets are gaining in importance for New Zealand and the EU; therefore, information on consumers' attitudes towards food attributes in these markets and how they differ from other markets is important information for New Zealand and EU producers and exporters.

This study included a survey conducted with a sample size of 1,000 in two developed countries (UK and Japan) and three developing countries (India, China, Indonesia) to assess consumers' attitudes towards credence attributes in food and beverages products.

Overall, this study found that credence attributes in food and beverages are important to consumers in China, India, Indonesia, Japan and the UK. In many cases, developing countries valued attributes more than developed countries. However, the relationship between the attributes and important factors underpinning those showed differences across the markets with participants from the developing countries tending to rate these more important than their counterparts from the developed countries.

In order to assess the potential impact of different premiums for food attributes on producer returns in the European Union (EU-28) and New Zealand, four scenarios were developed with varying levels of premiums for food attributes in three developing countries (India, China, Indonesia) and six developed countries (Australia, Canada, Europe Union (28), Korea, Japan and the United States of America). Overall, the impacts of different ranges of premiums for credence attributes in food products in the countries of interest were projected to increase EU and New Zealand producer returns for dairy, beef and sheep meat commodities by 2024. For New Zealand, significant increases of producer returns were projected for sheep meat, while EU producer returns were high for butter. 
To conclude, consumer preferences and attitudes for attributes in food and beverages differ across countries. However, these can have a positive impact on producer returns in the EU and New Zealand. 